\title{
Recent centrifuge modelling of offshore geotechnical problems at IWHR
}

\author{
Jianhui Liang, ${ }^{1, *}$, and Xianhui Song ${ }^{1}$ \\ ${ }^{1}$ China Institute of Water Resources and Hydropower Research, Beijing, China
}

\begin{abstract}
Centrifuge modelling has been proven to be an efficient and reliable approach for examining offshore geotechnical problems. This study reports the two series of centrifuge tests to understand the behaviour of spudcan penetration in a "soft-stiff-soft clay" stratigraphy and the behaviour of gravity anchor subjected to a lateral loading. A hydraulic system has been adopted to apply the large compressive and tensional load on the spudcan and gravity anchor, respectively. Load cells were installed on the base of the spudcan to directly measure the stress acting on the spudcan base. A 2D laser scanner was adopted to monitor the horizontal, vertical movement and tilting of the gravity anchor. The influence of the relative soil stiffness on the spudcan pentration behaviour and the soil deformation and interaction with the gravity anchor are discussed based on the centrifuge test results.
\end{abstract}

\section{Introduction}

Most of offshore geotechnical problems are relevant to foundations of the offshore structures, e.g., oil platforms, artificial islands and submarine pipelines. Due to the considerable difference in the onshore and offshore soil conditions, structural forms, etc., the construction experience and numerical models for the design of onshore structures cannot be directly adopted in the design of offshore structures. Hence, physical experiments, especially centrifuge model tests, are extremely needed in marine engineering.

This paper reports recent centrifuge modelling of offshore geotechnical problems at China Institute of Water Resources and Hydropower Research (IWHR). Fig. 1 shows pictures of the beam centrifuge and the associated monitoring system and control table at IWHR. The centrifuge has a diameter of $10.6 \mathrm{~m}$, an effective capacity of $450 \mathrm{~g} \cdot \mathrm{t}$, an effective payload of $1.5 \mathrm{t}$ and a maximum centrifugal acceleration of $300 \mathrm{~g}$. The inner dimensions of the basket for static tests are $1.5 \mathrm{~m} \times 1.0$ $\mathrm{m} \times 1.5 \mathrm{~m}$. The centrifuge is equipped with in-flight horizontal-vertical shaker, a four-axis robotic manipulator and an advanced data acquisition and control system. In the following text, the series of the centrifuge tests for understanding the spudcan penetration behaviour in a "soft-stiff-soft clay" stratigraphy are firstly described, followed by the tests to examine the behaviour of gravity anchors subjected to a lateral loading. In each part, the experimental details, results and discussions will be elaborated. At last, concluding remarks will be presented. (a)

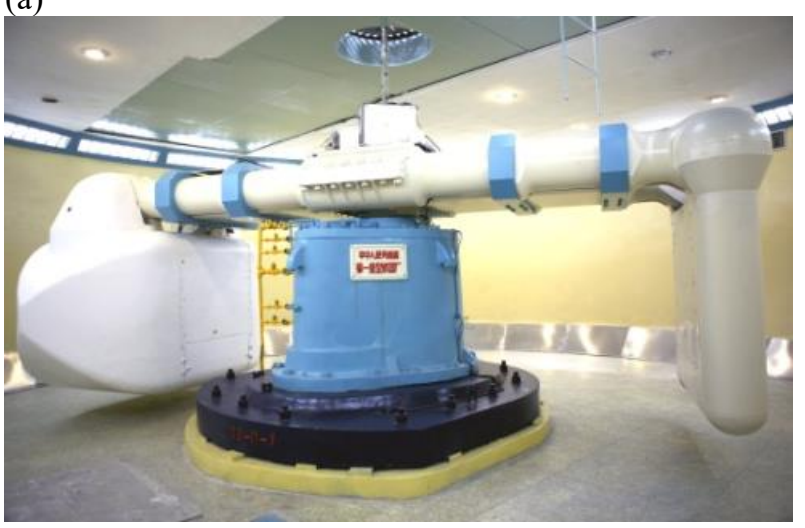

(b)

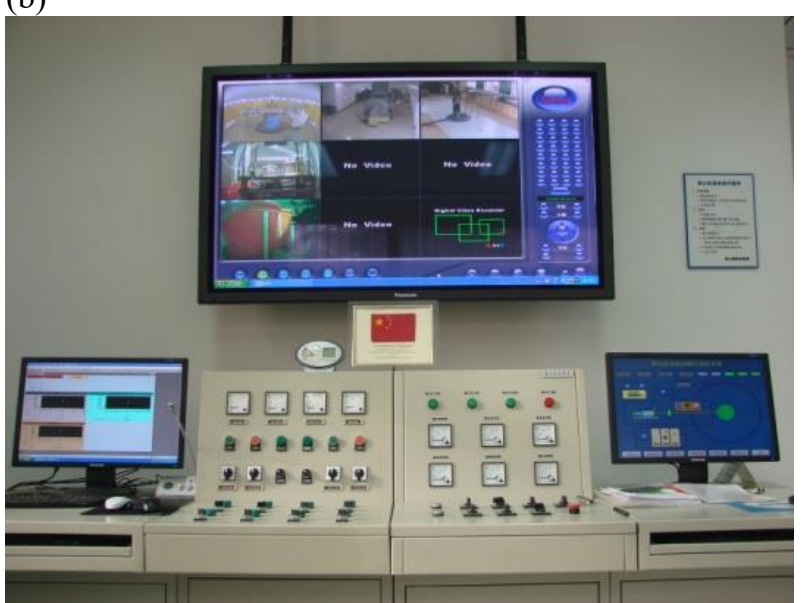

Fig. 1. Pictures of (a) the 450 g.t beam centrifuge and (b) the associated monitoring system and control table at IWHR 


\section{Spudcan penetration in a "soft-stiff- soft clay" stratigraphy}

Spudcans are used to support the legs of mobile jack-up rigs. During the installation of the spudcan in the seabed, a sudden rapid penetration, i.e., "punch-through", may occur if the underlying soil cannot resist the applied load. Such "punch-through" behaviour may lead to catastrophic damage to the platform, e.g., leg buckling or toppling of the unit. Based on Osborne ([1]), the punchthrough hazard is the most commonly encountered problem for jack-up foundations. Therefore, it is important to examine the penetration behaviour of spudcans in different soil profiles.

Centrifuge tests on "stiff-soft clay" (e.g., [2]), sand overlying normally consolidated clay (e.g., [3]) and "clay-sand-clay" stratigraphies (e.g., [4]) have been performed and valuable experimental data can be found in the literature. Since the "soft-stiff-soft clay" stratigraphy is one of the commonly encountered stratigraphies in China and such a stratigraphy has seldom been simulated in centrifuge, this study aims to examine the penetration behaviour of the spudcans in the stratigraphy. In the following text, the experimental details will be firstly presented, followed by the experimental results and discussions.

\subsection{Experimental details}

Three centrifuge tests denoted by T1, T2 and T3 have been carried out. As shown in Figs. 2a and 2b, a fullspudcan was used in each of the tests $\mathrm{T} 1$ and T2, where the spudcan was installed in the middle of the soil specimen. To monitor the variation in the displacement field in soil, as shown in Fig. 3. a half-spudcan was used in T3 and the spudcan was pushed into the subsoil along the transparent side wall. The spudcans used in all the tests have the same diameter, $180 \mathrm{~mm}$. At a $100 \mathrm{~g}$ centrifugal acceleration used in this study, the prototype diameter is $18 \mathrm{~m}$, which is in the range of typical diameters of spudcans in the field. It is noteworthy that the diameter of the spudcan model used in this study is much larger than those used in the literature, where the diameter is usually in the range of $30 \sim 100 \mathrm{~mm}$ (e.g., [24]). This requires a loading system with much larger capacity and better control precision. To meet this requirement, a hydraulic loading system has been designed (as shown in Fig. 2c).

As shown in Fig. 2d, for the spudcans used in tests 1and 2, three load cells were installed on the base of the spudcan to directly measure the soil stress acting on the spudcan base. To the best of our knowledge, this is the first time that the sensors have been mounted on the base of the spudcans. (a)

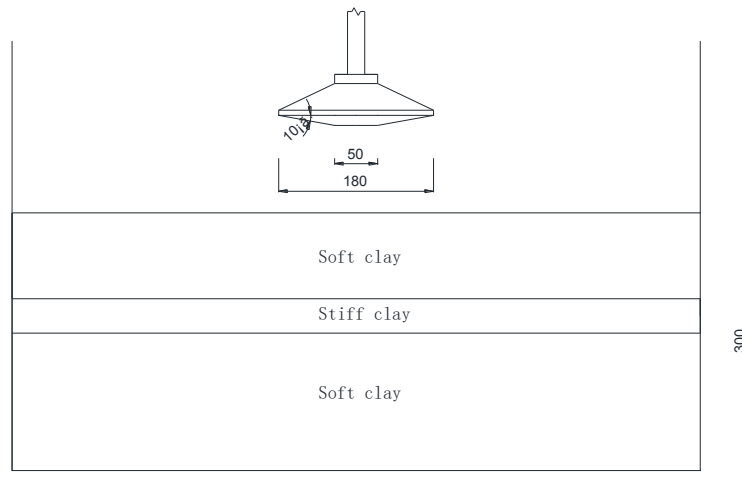

(b)

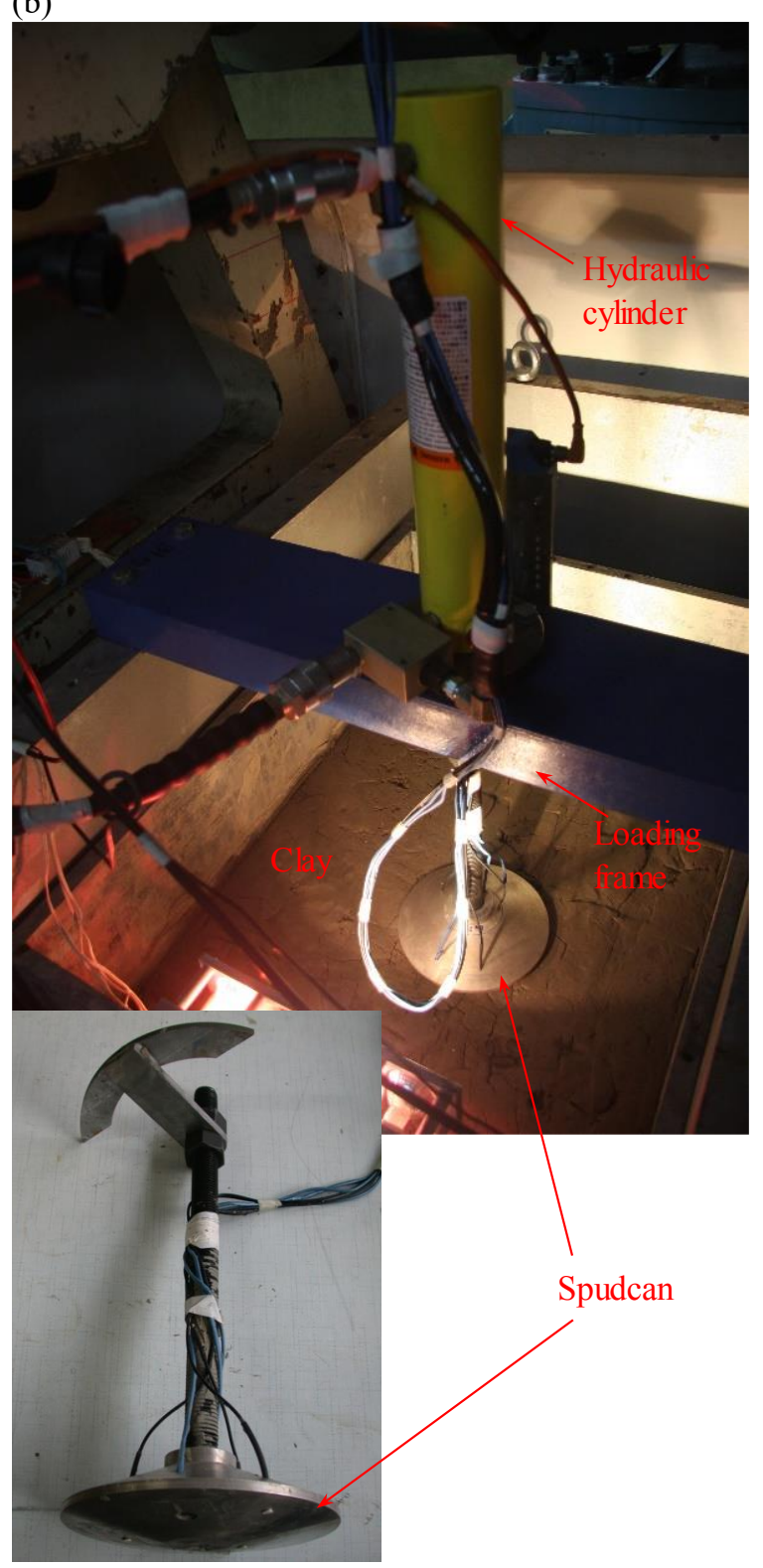


(c)

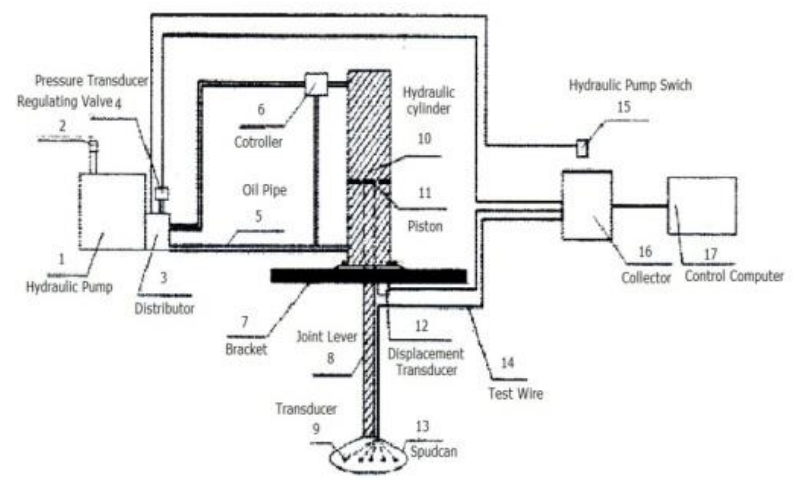

(d)

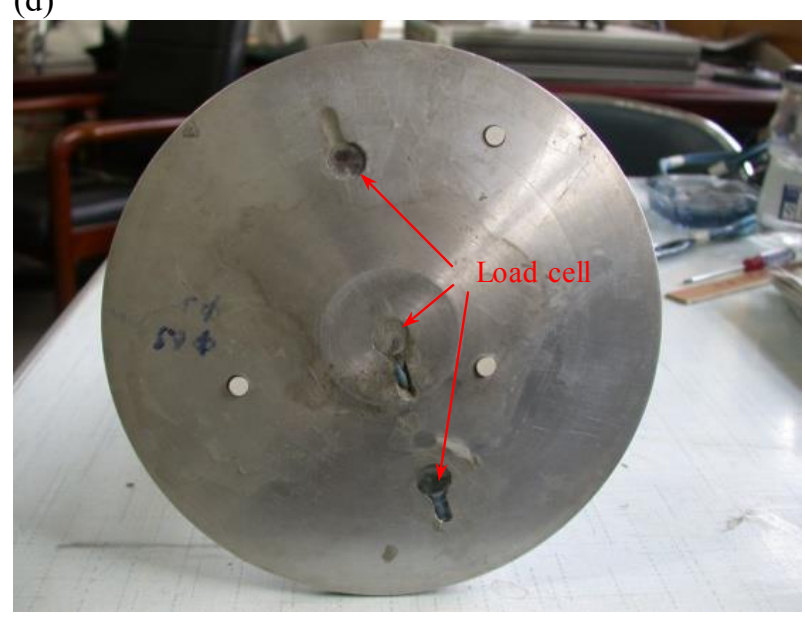

Fig. 2. Experimental setup: (a) Spudcan geometry and a schematic drawing of the soft-stiff-soft clay stratigraphy; (b) Picture of the model used in tests T1 and T2; (c) schematic drawing of the hydraulic loading system; and (d) load cells mounted on the spudcan used in tests $\mathrm{T} 1$ and $\mathrm{T} 2$.

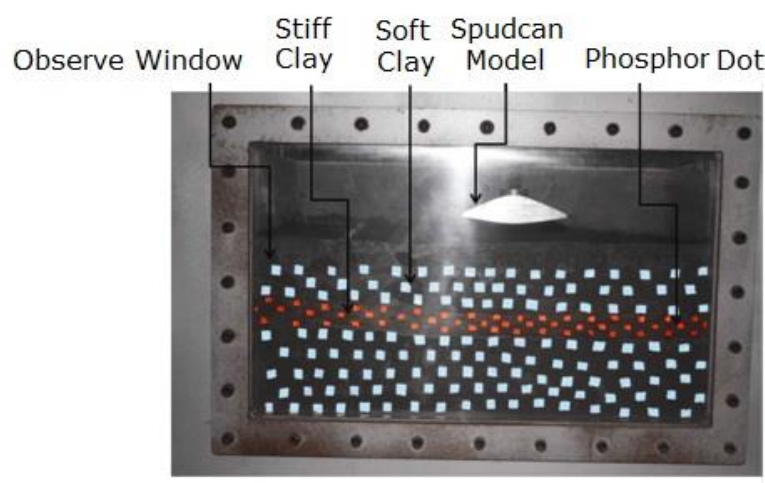

Container

Fig. 3. Picture of the model used in test T3.

Table 1 summarizes the geometries and soil properties of the centrifuge spudcan penetration tests. The experimental setups of the tests $\mathrm{T} 1$ and $\mathrm{T} 2$ have the same geometries of soil layers with a prototype $2 \mathrm{~m}$ thick middle stiff clay layer. The soil properties are different in the two tests. To ease the comparison, the undrained shear strength in the top and bottom soft clay layers are normalized by the value in middle stiff layer, The ratios

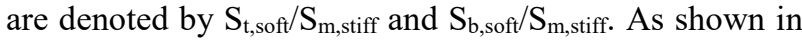
Table 1, both values of $S_{t, \text { soff }} / S_{m, s t i f f}$ and $S_{b, s o f t} / S_{m, s t i f f}$ are much smaller in $\mathrm{T} 2$ than those in T1. Hence, comparison of the two tests can help understand the effect of the stiffness of the middle layer relative to the top and bottom layer on the penetration behaviour. It is noteworthy that the undrained shear strength was obtained using vane shear tests. Details of the tests as well as the preparation method of the stratigraphies can be found in Li et al. ([5]). When the model was in-flight at $100 \mathrm{~g}$ centrifugal acceleration, the aforementioned loading system was used to gradually press the spudcan into the subsoil until a penetration depth of $20 \mathrm{~m}$ in prototype scale. Measurements from the load cells were constantly collected in tests $\mathrm{T} 1$ and $\mathrm{T} 2$, and particle image velocimetry (PIV) technique was adopted in test T3.

Table 1. Geometries and soil properties of the centrifuge spudcan penetration tests

\begin{tabular}{|l|l|l|l|}
\hline Test No. & T1 & T2 & T3 \\
\hline Spudcan type & Full & Full & Half \\
\hline $\mathrm{H}_{\mathrm{t}, \text { soft }}(\mathrm{m})$ & 10 & 10 & 10 \\
\hline $\mathrm{H}_{\mathrm{m}, \mathrm{stiff}}(\mathrm{m})$ & 2 & 2 & 2 \\
\hline $\mathrm{H}_{\mathrm{b}, \text { soft }}(\mathrm{m})$ & 18 & 18 & 18 \\
\hline $\mathrm{H}_{\mathrm{t}, \text { soff }} / \mathrm{D}$ & 0.56 & 0.56 & 0.56 \\
\hline $\mathrm{H}_{\mathrm{m}, \mathrm{stiff}} / \mathrm{D}$ & 0.11 & 0.11 & 0.11 \\
\hline $\mathrm{S}_{\mathrm{t}, \mathrm{soff}} / \mathrm{S}_{\mathrm{m}, \text { stiff }}$ & 0.5 & 0.23 & 0.55 \\
\hline $\mathrm{S}_{\mathrm{b}, \text { soft }} / \mathrm{S}_{\mathrm{m}, \mathrm{stiff}}$ & 0.51 & 0.35 & 0.59 \\
\hline
\end{tabular}

\subsection{Results and discussions}

Fig. 4 presents a comparison of the stresses acting on the spudcan base at different penetration depths in tests 1 and 2 . Since the difference in the undrained strength of the soft and stiff layers is relatively small in test $\mathrm{T} 1$, no peak stress has been observed. However, when the ratios

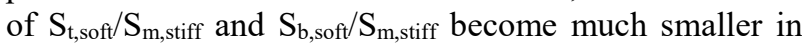
$\mathrm{T} 2$, the penetration resistance reaches its maximum value at about the interface between the top soft clay and stiff clay and then decreases with increasing the penetration depth, which indicates the punch-through behaviour. Hence, similar to the experimental results in "clay-sandclay" stratigraphy reported in Ullah et al. ([4]), the risk of "punch through" decreases with increasing the ratio of stiffness of the soft clay over that of the imbedded stiff clay layer. When such a ratio is larger than 0.5 , the "punch through" can hardly occur. However, the spudcan penetration will exhibit "punch through" behaviour when the ratio decreases to 0.2 . The development of the displacement field during spudcan penetration obtained in $\mathrm{T} 3$ has been reported in $\mathrm{Li}$ et al. ([5]). Li et al. ([5]) also performed finite element method (FEM) simulations on those centrifuge tests. The simulation results demonstrate that the plastic zones evolve differently for different ratios of $\mathrm{S}_{\mathrm{t}, \text { soft }} / \mathrm{S}_{\mathrm{m}, \text { stiff }}$ and $\mathrm{S}_{\mathrm{b} \text { soft }} / \mathrm{S}_{\mathrm{m} \text {,stiff }}$ and the failure mechanism is highly affected by those ratios. Please refer to that paper for more information. 


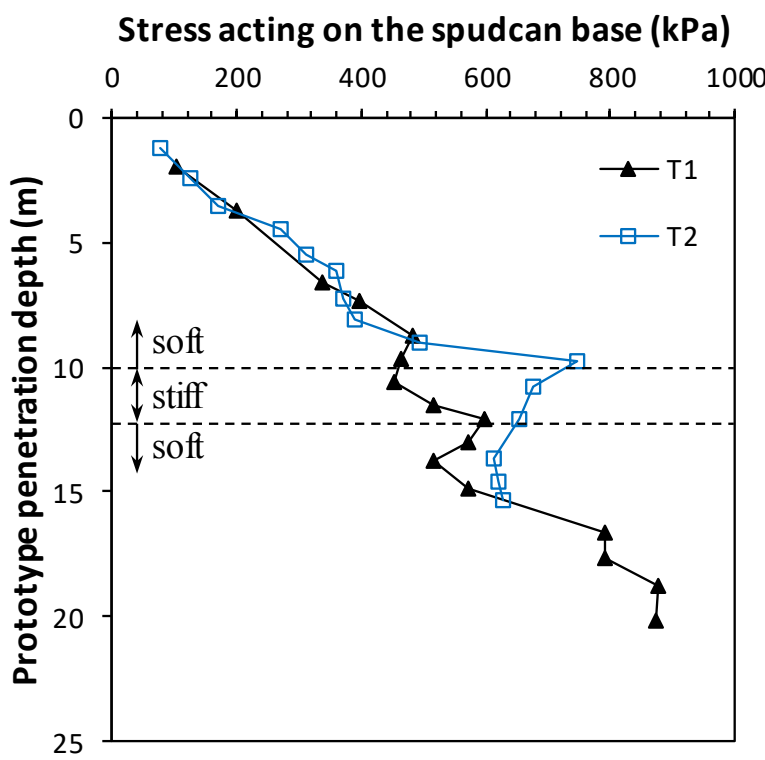

Fig. 4. Comparison of the load-penetration depth response for different soft clay stiffness in the soft-stiff-soft clay stratigraphy

\section{Behaviour of gravity anchor subjected to a lateral loading}

Gravity anchors have been used for deep water mooring for many years. The lateral bearing capacity of the gravity anchor is crucial in the design of the mooring system. Failure of the gravity anchors may cause catastrophic damage to the platform. Nowadays, new forms of gravity anchors have been proposed. The behaviour of those gravity anchors subjected to a lateral loading needs to be further explored. In order to examine such behaviour, a series of centrifuge tests using different gravity anchor forms and seabed soil types have been carried out at IWHR. In the following text, the experimental details will be firstly presented, followed by preliminary experimental results.

\subsection{Experimental details}

Figs. 5 and 6 present the experimental setup of the centrifuge tests. In each model, the anchor was placed on a layer of calcareous sand and was immersed in water. The aforementioned hydraulic loading system was modified and then adopted in this study to pull the anchor forward. Since the anchor was immersed, the movement of anchor can hardly be monitored using laser displacement sensors. To solve this problem, a thin plate was installed on the surface of the anchor. A 2D laser scanner was used to measure the settlement, horizontal displacement and tilting angle of the anchor. Fig. 7 shows the forms of gravity anchors used in this study. The centrifugal acceleration used in this study is $15 \mathrm{~g}$.

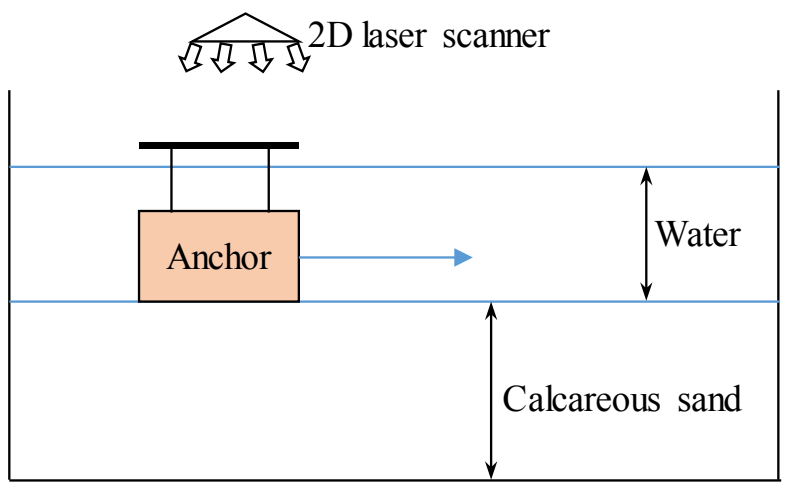

Fig. 5. A schematic drawing of the experimental setup of the centrifuge testes to explore the gravity anchor behaviour

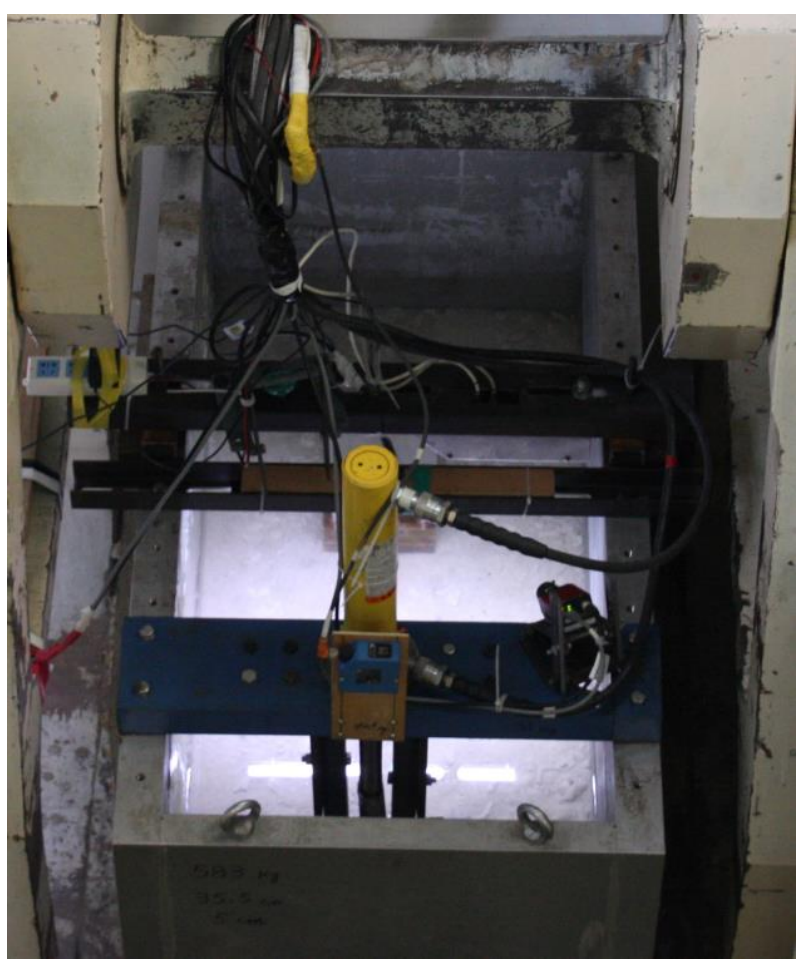

Fig. 6. A picture of the experimental setup of the centrifuge testes to explore the gravity anchor behaviour

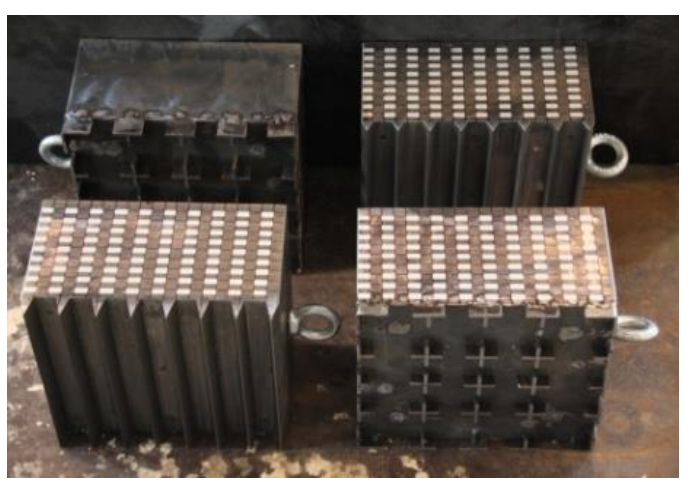

Fig. 7. Different forms of gravity anchors

\subsection{Preliminary experimental results}

Fig. 8 presents the movement of the anchor and the deformation of the calcareous sand layer. During the 
horizontal movement of the anchor, the anchor gradually settles. There is a larger settlement in its front part than that in the back part. In other words, the anchor tilts during the process. This is due to the fact that the moment of the pulling force requires larger vertical stress applied on the front anchor base to provide the counterbalance moment. Such larger vertical stress is accompanied by a larger deformation of the soil at the front of the anchor, i.e., a larger settlement. With the movement of the anchor, the sand particles in the front of the anchor moves horizontally and form a small "hill". The force acting on the front surface of the anchor plays an important role to resisting the pulling force. The stress distribution on the from and bottom surfaces of the anchors needs to be further analysed.

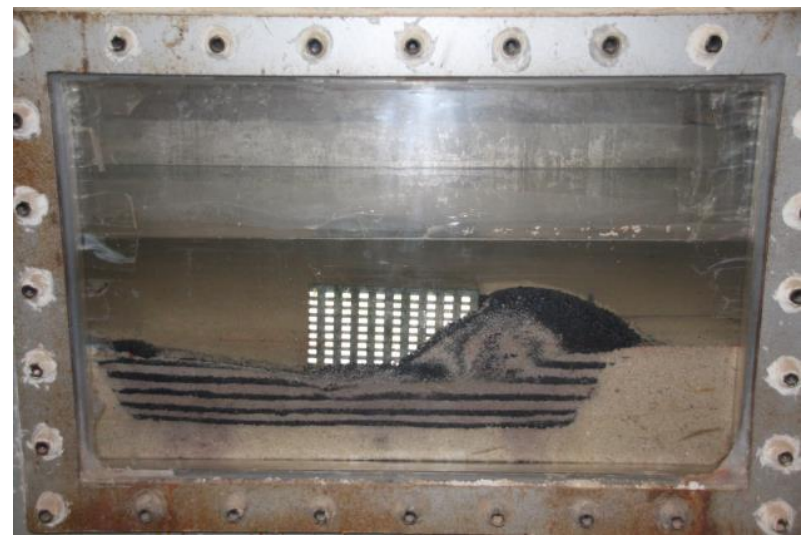

Fig. 8. Preliminary results: movement of the gravity anchor and deformation of the calcareous sand

\section{Concluding remarks}

This paper reports recent centrifuge modelling of offshore geotechnical problems at IWHR. The first group of centrifuge tests is to examine spudcan penetration behaviour in a "soft-stiff-soft clay" stratigraphy. A hydraulic loading system was designed to penetrate the model spudcan, which is much larger than those reported in the literature. Load cells installed on the base of the spudcan were adopted to directly monitor the stress acting on the base, which is an approach firstly used in this kind of centrifuge model tests. The experimental results demonstrate that the risk of "punch through" decreases with increasing the ratio of stiffness of the soft clay over that of the imbedded stiff clay layer. When such a ratio is larger than 0.5 , the "punch through" can hardly occur. However, the spudcan penetration will exhibit "punch through" behaviour when the ratio decreases to 0.2 .

In the second group of centrifuge tests to explore the behaviour of gravity anchors subjected to a lateral loading, the aforementioned hydraulic system was modified to provide the pulling force, and a 2D laser scan sensor was used to monitor the horizontal, vertical displacement and tilting of the gravity anchor. The preliminary results indicate a relatively larger settlement on the front part of the anchor and that the sand has been pushed to form a "hill" in front of the anchor, which plays an important role in resisting the pulling force.
This research was supported by National Key R\&D Program of China (SQ2017YFSF060085) and IWHR Research and Development Support Program (GE0145B102017 \& GE0145B122019). The authors are grateful to the reviewers for their valuable comments.

\section{References}

1. J.J. Osborne, Are we good or are we lucky? Managing the mudline risk. Proceedings of OGP/CORE Workshop: the jack-up drilling optioningredient for success, Singapore (CDROM). (2005)

2. M.S. Hossain, M.F. Randolph, Deep-penetrating spudcan foundations on layered clays: centrifuge tests Géotechnique, 60, 157-170. (2010)

3. K.L. Teh, C.F. Leung, Y.K. Chow, M.J. Cassid, Centrifuge model study of spudcan penetration in sand overlying clay, Géotechnique, 60, 825-842. (2010)

4. S.N. Ullah, S. Stanier, Y. Hu, D. White, Foundation punch-through in clay with sand: centrifuge modelling Géotechnique, 67, 870-889. (2017)

5. S. Li, Y.C. Wang, X.Z.Wu, J.H. Liang, Y.R. Zhou, Centrifugal model tests on mechanism of spudcan penetration of jack-up drilling platform in egg-shell layered soil. Chinese J. Geotech. Eng., 37, 479-486 (in Chinese). (2015) 